\title{
The lifecycle of Qaf in Jordan
}

\author{
Enam Al-Wer \\ University of Essex, enama@essex.ac.uk \\ Bruno Herin \\ Université Libre de Bruxelles, bruno.herin@ulb.ac.be
}

\section{Introduction}

In Weinreich, Labov and Herzog 1968 article Empirical foundations for a theory of language change, five problems are outlined for a theory of language change to address. These are: the actuation problem; the constraints problem; the transition problem; the embedding problem; and the evaluation problem. This article addresses some of these issues in discussing the lifecycle of the variable Qaf in Jordan.

The variable Qaf is often described as the best studied sociolinguistic variable in Arabic, but it is noticeable that our knowledge of the progression from Form A to Form B in relation to this variable has crucial gaps. For instance, the evaluation problem is too often resolved by appealing to notions of 'prestige', 'stigma', 'femininity versus masculinity', 'urban versus rural' without prior analysis of the empirical factors which have led to the emergence of these social values, nor the evolution in their meanings and significance. When a change is completed or nearing completion, it becomes much more difficult to analyse the social conditions under which the change occurred. A case in point is the dialect of the Palestinian city of Nablus, where the change from [q] to glottal stop [?] appears to have been completed, but no analysis is available of this case and any future attempts to interpret it are likely to be highly speculative given the advanced stage of the change. 
However, the change affecting Qaf continues to be operative in a number of other dialects in the Levant region, most notably in Jordanian dialects ${ }^{1}$. In these dialects, while the target variant is also [?], the variant which gives way is $[\mathrm{g}]$, a sound that symbolises a series of attributes, which are rated differently by different sectors of the community. The rise in the level of social awareness and the emergence of stereotypes associated with the use of one or the other variant are symptoms of the progression of the change in the speech community.

On the basis of linguistic data gathered by the authors in a number of localities in Jordan, including the capital city Amman, and an analysis of the relevant socioeconomic and political developments in the country, the article investigates the lifecycle of this variable, addressing questions of the inciting causes of the variation in the first place, transition from one social group to another, and the embedding of the change as it progresses in the social system of the community. The value of an explanation that provides a rigorous analysis of the linguistic data in relation to the social context lies in its potential generality. The aim is for the analysis we put forward to provide such possibilities of generalisation.

\section{The status of Qaf}

\subsection{When Qaf is not a variable}

Sociolinguistic studies of variation and change in Mashreqi Arabic almost always include (q) as one of the variables worth investigating. Often (q) is considered the most salient of all variables as can be witnessed by the fact that its variants are frequently used to label dialects. Thus, one finds labels such as gilit dialects to refer to the Mesopotamian dialects which use the variant [g] traditionally (e.g. Muslim Baghdadi), qeltu dialects to refer to those that use [q] (e.g. Christian \& Jewish Baghdadi), and [?] dialects (e.g. Jerusalem) and $[\mathrm{k}]$ dialects (e.g. rural central/northern West Bank Palestinian) to refer to dialects that use [?] and [k] respectively. But while in many cases the choice of (q) as a linguistic variable is justified by virtue of the fact that different variants occur variably in the vernacular, in other cases the designation of (q) as a variable is doubtful. In the latter cases, the variation found involves the use of $[\mathrm{q}]$ in standard pronunciations but it is not ordinarily found as a vernacular form. The dialect of Damascus is a case in point: in the traditional dialect, the glottal stop is the normal realisation, and the occurrence of $[\mathrm{q}]$ is largely confined to learned lexical items which may be borrowed from the standard in semi-casual speech

1. For instance, see the results in: Abdel-Jawad 1981, Al-Khatib 1988, Al-Wer 1991, Al-Wer 2007; and the comments in this regard in Herin 2010. 
and/or in formal monitored speech where the use of standard lexemes is generally unavoidable. In such cases, there is no systematic variation between [?] and [q] in the vernacular, and thus [q] cannot be claimed to be a variant of the same phonological unit as the glottal stop. Since in this case the glottal stop does not vary with other variants in the vernacular, (q) is obviously not a linguistic variable in Damascus. The same is true in both Beirut and Jerusalem (and in many other localities in Peninsula dialects). For Cairo, Haeri (1997) has looked at the distribution of [q] in her sample and concluded that its occurrence is not governed by a structural rule but by lexical choice. She has further proposed that the [q] word class (which principally consists of lexical borrowings from the standard) has been added to the Cairo dialect system as a parallel system (without full integration), and thus the occurrence of [q] in the speech of the native speakers should not be taken to indicate a 'restoration' of [q] (and thus a reversal of a historical sound merger) (also see Labov 1994: 342-348).

\subsection{Qaf as a variable in Jordan}

With reference to (q) as a variable, the situation in Damascus contrasts quite sharply with the current situation in Amman. In this case, although similarly to Damascus and Beirut the occurrence of the standard variant [q] is lexically conditioned (see Abdel-Jawad 1981), Qaf is indeed a variable whose variants, [g] and [?], co-occur in the same lexical items irrespective of the speakers dialectal background for some groups. Thus, /galla:jit bandorra/ and /Ralla:jit bandorra/ refer to the same traditional recipe 'fried tomatoes'; and items like /gami:s/, /Ramis/ co-occur in the speech of the same speaker to refer to the same clothing item 'shirt'. Abdel-Jawad 1981 also investigated the use of [k] as a variant of (q) in Amman. This variant is found only in the speech of the sector of the population of Amman who originally came from central and northern West Bank villages and towns (e.g. Jinin, Qalqilya, Beit Jala, etc.), but $[\mathrm{k}]$ is recessive since speakers of such rural Palestinian origins abandon it in favour of either [g] or [?] (or both at the same time), and it is not used by speakers from other dialectal backgrounds. This finding has been confirmed by the research carried out by Al-Wer (2002).

The variation in the use of Qaf in Amman and other Jordanian localities thus involves two variants: $[\mathrm{g}]$ and [?]. This variability resulted from frequent face to face interaction between speakers of the indigenous Jordanian dialects or speakers of $[\mathrm{g}]$ dialects, and speakers of various other Levantine dialects, most importantly Palestinian city dialects or [?] 
dialects. In the Amman speech community as a whole, the presence of the variation is additionally due to dialect mixture since a sizable proportion of the City's population immigrated to Amman from Palestinian cities, which have [?] as the dialectal form of (q).

The empirical data available from various Jordanian localities strongly suggest that the $[\mathrm{g}]$ - [?] variation has spread horizontally (to more locations) and vertically in the sense that increasingly it is found in the speech of more social groups within the same speech community ${ }^{2}$, which indicates that a change from $[\mathrm{g}]$ to [?] may be in progress. In fact the change to completion can be seen in some female speech in Amman: the youngest speakers who grew up in a $[\mathrm{g}]$-speaking environment use [?] consistently (and thus show no variation) (see Al-Wer 2007). So, how did this situation come about? What are the mechanisms via which speakers gradually adopt the new variant? What are the social constraints on the variation? Have the constraints evolved over time and have new ones emerged? Are new constraints mutations of the old ones? These issues are addressed in the sections to follow.

\section{Qaf in the traditional dialects of Jordan}

The earliest record available of the linguistic features characteristic of the dialects spoken east of the River Jordan is Bergsträsser's atlas of 1915. With respect to Qaf, the whole region is designated as a $[\mathrm{g}]$-speaking region. This designation can be further corroborated by the data collected in 1987 from the cities of Sult, Ajloun and Kerak ${ }^{3}$ (Al-Wer 1991). A few of the speakers recorded in these locations were born at the turn of the $20^{\text {th }}$ century, and one speaker was born in 1897 . On the basis of these data, and the information cited below, we can state with confidence that all of the traditional dialects of Jordan have $[\mathrm{g}]$.

A second layer of information on the state of Qaf in the same locations mentioned above can be obtained from Al-Wer's pilot study in

2. In addition to the results in Abdel-Jawad 1981, see also Al-Khatib 1988 and Al-Wer 1991. The last two studies are particularly significant because they report on communities outside Amman. The number of Palestinian speakers of [?] dialects in the cities of Sult, Ajloun, and Kerak in particular is negligible in comparison to Amman.

3. In relation to Amman, Sult is $20 \mathrm{~km}$ northwest, Ajloun is $70 \mathrm{~km}$ northwest and Kerak is $130 \mathrm{~km}$ south. This covers an area of some $200 \mathrm{~km}$ in length, and includes the three dialectal regions of Jordan: Horan (Ajloun), Balga (Sult) and Mu'ab (Kerak). The dialects spoken further south, from Ma'an to the Saudi border, are generally of the Hijazi type (not Levantine type), (these locations are marked on the map appended to this article); see Cleveland (1963) for a classification of the dialects of Jordan. 
1987. A total of forty speakers were piloted to check the viability of the linguistic and social variables. The results showed that none of the male speakers diverged from the traditional dialects in their use of the four linguistic variables included in the study. ${ }^{4}$ The sample of the speakers who participated in the main research included 117 women, covering an age range of 18-90 at the time of the research. No variation between $[\mathrm{g}]$ and [?] was found in Kerak and only one speaker in Ajloun used [?] consistently; two further speakers in Ajloun used it sporadically (3 out of 22 tokens). In Sult, there were five speakers (out of 40) who used the glottal stop consistently ${ }^{5}$. The youngest speaker who used the glottal stop was born in 1969 but her mother who was 50 years old at the time did not use [?] at all. Therefore, almost certainly the youngest speaker herself did not acquire the glottal stop from home during her formative years ${ }^{6}$. This then means that roughly speaking Qaf emerged as a variable among the native speakers of Jordanian dialects in the provincial towns only during the late 1970s, and its use in 1987 was confined to a few individuals in the location nearest to Amman (Sult). The fact that variation was found only in the speech of women strongly suggests that the use of the glottal stop in the provincial towns was an innovation introduced by the female speakers. Furthermore, since the presence or absence of the glottal stop showed correlation with distance from Amman, most likely the capital city was where the innovation started. From this centre the innovation radiated northwards, affecting nearby locations (Sult) before reaching farther away locations (such as Ajloun). At the time of research, the southern city of Kerak was as yet unaffected.

The suggestion that Qaf emerged as a variable among the native speakers of Jordanian dialects during the 1970s coincides with a period of stabilisation in the population of Amman. Until the 1930s, Amman itself was a little town with a population of only about 10,000, whereas the population of Sult was at least triple this number. Half of Amman's population at the time were Circassian in origin and tongue. The other half included migrants mainly from the Jordanian city of Sult, the Palestinian city of Nablus and a handful of families from Syria. A population boom occurred firstly after the 1948 war, which brought in Palestinian refu-

4. In addition to Qaf, the interdentals and Jim were investigated in this study.

5. The consistent usage of the glottal stop means that these speakers showed no variation but total abandonment of the traditional variant. See Al-Wer 1991 for an analysis of this result.

6. There were 2 further speakers of the same age from Sult and none of them used the glottal stop. 
gees from the part of Palestine that became Israel. As the population of Amman was stabilising in the 1960s, another wave of Palestinian refugees arrived after the 1967 war. The country was in political turmoil until 1974 followed by a period of relative stability until the early 1990's when more refugees arrived from Kuwait and later waves of refugees intermittently arrived from Iraq. We are thus suggesting that some sort of stability in Amman was a prerequisite for it to assume the status of a linguistic centre out of which linguistic innovations will radiate, and that in the history of the City this stability was the period roughly between 1974-1992.

Further information on the progress of the variation in the use of Qaf can be gleaned from a small-scale research in Sult carried out by Al-Wer in 1997. In this research, samples of speech were obtained from 8 young speakers (in their early 20s), four of each sex. The 1997 data overall showed that the male speakers continued the trend of the former generations by consistently using the local variant $[\mathrm{g}]$, i.e. there was no variation in the use of Qaf. This was not a surprising result given the social constraints of 'gender' and 'localness', as will be explained later. Crucially though, the young men of Sult in the 1997 research diverged from the patterns showed by the previous generations of male speakers by participating in the variation that involved the interdental sounds. This is an important result because it indicates that the male speakers in Sult do participate in variation that involves a non-local linguistic innovation (albeit at a much slower rate), and their failure or reluctance to participate in the Qaf variation is itself meaningful, as will be explained further below. In the female speakers' data although there was still a high degree of maintenance of the local variant $[\mathrm{g}]$, all four girls showed some variation in Qaf, thus indicating an increase in the presence of this variation in the community as a whole.

The final source of information by way of an update of the state of Qaf variation in the traditional dialect of Sult and its environs comes from the research by Herin which began in 2005 (Herin 2010). Herin's study aimed at providing a description of the traditional dialect of the city, and thus the methodology and sample of speakers focused on obtaining samples of speech from the oldest and least mobile members of the community. Herin's sample was also not confined to the city itself but included one nearby town within the governorate, namely Fuheis, which is nearer to Amman. The data provided by this study increase our confidence in the stages set out (see below) of the history of the variable as well as the mechanisms of its progression in the speech community as a whole. Herin found no variation between $[\mathrm{g}]$ and glottal stop in 15 hours of recordings, 
which confirms our suggestion that the variation in Qaf is a relatively recent development in Jordanian dialects and that it emerged as a result of contact with non-local dialects. Furthermore, Herin's data indicate that the variation has been circulating more or less among the same social groups (the mobile and relatively young members of the community) without diffusing across to other social groups or older age cohorts.

With this information in mind, we now turn our attention to the dialect and community of Amman, which, as we have suggested, is the source of variation in Qaf.

\section{Amman: community and dialect}

Unlike the city of Sult, which has had an uninterrupted history of stable close-knit community and a distinctive local dialect, Amman, the ancient Ammonite city of Rabbath Ammon and Roman Philadelphia lay in ruins during $7^{\text {th }}-20^{\text {th }}$ centuries. When it was declared the capital city of the Emirate of Trans-Jordan (Later the Kingdom of Jordan) it was inhabited by a few thousand people who originally came from various places, in addition to the Circassian community for whom Amman became home after they were forced to leave their homeland in the north Caucasus. The Circassians did not speak Arabic upon arrival in 1876, and for decades remained largely monolingual. Neither their heritage language, Adyge, nor the varieties of Jordanian Arabic they later acquired through exposure and contact with the local Arabic-speaking population have had any impact on the formation of the dialect of Amman ${ }^{7}$. To all intents and purposes, the whole population of modern Amman can be considered migrants. In terms of regional origins, they can be divided into two groups. The first group consists of migrants from other Jordanian towns and villages, who spoke indigenous Jordanian dialects. The second group are originally Palestinians. In relation to their time of arrival, the Palestinians can be further divided into free migrants, who have lived in Jordan since the early decades of the $20^{\text {th }}$ century or earlier, and the war refugees who were displaced from their homes in historical Palestine as a result of the establishment of the State of Israel in 1948 and the occupation of the West Bank in 1967. The Palestinian dialects show sharp distinctions between three types: urban or city dialects, rural or village dialects, and Bedouin dialects. All three types of Palestinian dialects can be found in Amman.

7. Although the Circassians played no role in the linguistic developments witnessed in Amman, they have played a significant political role, especially as high-ranking officials in the State bureaucracy and armed forces. 
In the absence of a native and stable community, Amman naturally had no native traditional dialect. Until the 1980s, the linguistic situation in the City was largely characterised by unsystematic mixture of features from different dialectal stock. A project was launched in 1998 by Enam Al-Wer to investigate the linguistic situation in the City. So far, thirteen phonological and morpho-syntactic features have been analysed, and the results overall show that a distinctive Ammani dialect is at a fairly advanced stage of focussing. The emerging dialect contains a number of totally new features and new patterns not found in the input Jordanian or Palestinian dialects, as well as features which come from two sources: Jordanian dialects and urban Palestinian dialects.

For the purpose of the current discussion, in the remaining sections of this article we shall be focussing on the results concerning Qaf. Firstly though, a few necessary details about the methods followed in categorising the speakers ${ }^{8}$.

\subsection{The Amman research}

In the first stage of the research in Amman the focus was on obtaining samples of speech from the three generations of the City's inhabitants from each sector of the population. The speakers represented three generations of four families. Two families were originally from the city of Sult and the other two originally came from Nablus. Up to $97 \%$ of the original Arabic-speaking settlers in Amman came from Sult and Nablus, and therefore it was assumed that the dialects of these particular locations would form the major input dialects. In this sample of the research there are 8 speakers from the first generation, 8 speakers from the second generation and 14 speakers from the third generation. The second stage added 6 further speakers to the third generation. In total, the sample so far includes 36 speakers. With respect to the general linguistic behaviour of the three generations, the analysis shows the following patterns:

- First generation speakers. These speakers arrived in the City as adults. Their speech shows almost consistent adherence to the features found in the heritage dialects, although some "rudimentary levelling" is also present ${ }^{\text {? }}$.

- Second generation speakers were either born in the City or arrived as young children. Their speech exhibits extreme and unsystematic

8. Readers are referred to Al-Wer 2002, $2003 \& 2007$ for full details of the research methodology and analysis.

9. Trudgill (2004: 89-93) defines rudimentary levelling as the early levelling out of the most localised and most marked features in the koineisation process. 
inter-speaker and intra-speaker variability as a result of using a mixture of features from the two input varieties

- Third generation speakers were all born in Amman. The mixture found in their parents' speech is considerably reduced. Most importantly, in the speech of this generation one finds structured variability and an orderly linguistic behaviour.

\subsection{Qaf in Amman: the patterns}

Variation in Qaf in Amman involves the two variants [g] and [?]. These variants are in the first place regional variants. Traditional Jordanian dialects have [g] while urban Palestinian dialects have [?]. It is worth mentioning at this point that the urban Palestinian dialects share this features with the other major dialects in the Levant region as a whole, such as feature the dialects of Damascus, Beirut, Aleppo and Jerusalem. In this sense, [2] can be considered as a supra-local variant ${ }^{10}$. On the other hand, the variant $[\mathrm{g}]$ is characteristic of less dominant, more provincial dialects although it can be found in all of the dialects in southern Syria. In the Levant region, $[\mathrm{g}]$ can be considered as a localised feature ${ }^{11}$. As will be explained presently, in addition to regional affiliation, the Qaf variants have come to be associated with a range of social values.

The results from Amman show that across the three generations, gender has a consistent effect, although it interacts with other social variables differently in different generations. The results for each generation are outlined below.

In the first generation, there is a high degree of maintenance of the respective heritage variants. However, two groups of speakers diverged from this pattern. The Palestinian men, whose heritage variant is the glottal stop, used a few tokens of Jordanian [g] (7/52 tokens), as in /gallo/ 'he told him', /lage:na/ 'we found'. The other group that showed divergence from the heritage dialect was the Jordanian women, who used a few tokens of the glottal stop (5/48 tokens), as in the follow-

10. The notions supra-local versus localised features were first introduced by J. Milroy et al. (1994) to explain some gender-differentiated patterns in the use of the glottal variants in Tyne Side English (Northeast of England).

11. In Arabic dialectology [g] is commonly referred to as a Bedouin feature. We stress here that while designations such as 'Bedouin' and 'sedentary' may be appropriate for a general classification of Arabic dialects, they are superficial and can be misleading in sociolinguistics since they carry no explanatory value. Notice in this context for instance that while the variant $[\mathrm{g}]$ is localised in the Levant (and in Egypt) it is supra-local in the Gulf region (and in Saudi dialects), which is what explains its marginal status in the former region but dominance in the latter region. 
ing examples: /Ri:mi/ 'remove!', /bitsu:?/ 'she drives (her car)'. The remaining sub-groups, the Palestinian women and the Jordanian men consistently used their respective heritage variants and thus showed no variation in Qaf. We can conclude that in the speech of this generation, there is a straightforward correlation between regional, and at the same time, ethnic affiliation and the use of Qaf. As we will see later, the divergences by the Palestinian men and the Jordanian women of this generation, although relatively low in frequency, are the first signs of some of the trends that became established in successive generations.

In the second generation, there is no change to the patterns found among the most conservative groups, the Jordanian men and the Palestinian women. These groups continue to use their heritage variants consistently. On the other hand, the divergence we saw above on the part of the Jordanian women and the Palestinian men increases considerably. In this generation, the Jordanian women use [?] predominantly (65/74 tokens) and the Palestinian men use the Jordanian variant [g] in nearly $50 \%$ of the total number of tokens (59). These are important results as they point to a complication of the total number of tokens (59) in the socio-linguistic correlation of Qaf variants: whereas in the first generation we see a straightforward correlation between dialectal (or ethnic) background and the use of Qaf variants, in this generation gender differentiation emerges as an important variable and the significance of ethnicity (or dialectal background) is blurred since speakers from both backgrounds use both variants. For the diverging groups, there appears to be a conflict between two dimensions which point in opposite directions. Ethnicity in the case of the Palestinians points in the direction of [?] but gender points in the direction of [g]. Conversely, for the Jordanian women ethnicity points towards the maintenance of [g], but gender points towards adopting [?]. We will see later how this pattern is further complicated by additional factors.

Before presenting the patterns found in the youngest generation, it is worth mentioning that the methods of data collection among this group of speakers included in addition to individual and group interviews, observations gathered by the fieldworker (the first author) through participation in their leisure activities ${ }^{12}$. The data gathered through observations were recorded in the form of fieldwork notes and were not quantified. The aim at this stage of research was to establish

12. Most of the speakers in this group were interviewed during the summer school holiday. The fieldworker socialised with different sub-groups in various leisurely activities at sports clubs and cafés and at their homes. 
the patterns of usage in as many different contexts as was feasible. These data will be corroborated with more systematic observations in later stages of the project.

In the third generation, there are two important developments. Firstly, in addition to gender and ethnic affiliation, context and interlocutor emerge as further constraints on the choice between Qaf variants. Secondly, gender emerges as the major organising category while ethnic affiliation assumes a subsidiary role in influencing the speakers' choices. The results are summarised below.

- The female speakers. Irrespective of their heritage dialects, they use the glottal stop consistently. We can say that this group of speakers advance the pattern established by the previous generations.

- The male speakers. This group of speakers are the most innovative and show the most complex patterns of associations, where all three social variables, ethnicity, gender and interlocutor/context, interact in a complex way. In in-group interactions (same ethnicity and within the family), the boys generally adhere to their respective heritage variants. When interacting with girls whether individually or in groups, both groups of boys tend to use the glottal stop. In ethnically mixed all-male interactions and especially in disputes of various sorts, the boys generally use $[\mathrm{g}]$. While, as we saw above, the female speakers simply advance the pattern that was set out by their mothers' and, to some extent, grandmothers' generations the boys do a lot more work. Their choices are constrained by three variables: dialectal background, gender and context. In this generation, we find the male speakers using $[?]$ and $[\mathrm{g}]$ in a clearly structured way for the first time (constrained by context and interlocutor). For the male group in this generation, none of the social variables correlate with linguistic usage in a simple way as both variants can be used by both ethnic groups in different contexts.

The results outlined above are discussed and analysed in the next section.

\subsection{Discussion of the results}

The correlation between Qaf variants on the one hand and ethnic affiliation, gender and context on the other are gradually added as layers of constraints on linguistic usage. The questions are: how can we explain the emergence of these factors? And, how are they related to the social context? To address the issues implied, we begin with an analysis of the socio-political environment in which these associations emerged in the first place. 
It is clear from the behaviour of the female speakers in the third generation that there is a correlation between gender (in the sense of sex of the speaker) and use of the glottal stop. It is equally clear from the behaviour of the male speakers in the first and second generations particularly that there is an association between male speech and the use of $[\mathrm{g}]$. Important for our analysis at this stage is the observation that it is the women who lead the divergence from [g], witnessed particularly in the second generation, i.e. for some reason, Jordanian women became increasingly attracted to the glottal stop. This generation of speakers were born during 1938-1948. At that time, Jordan was the least developed in the region, with no urban centres to speak of and no institutions of higher education. Jordanians looked to places like Damascus, Beirut, Haifa, and Cairo as places of culture and modernity. It is therefore not at all surprising that the linguistic features associated with the dialects spoken in these cities symbolised a modern outlook and an attractive lifestyle. At this juncture, it has to be assumed that men as well as women were attracted to the linguistic and other attributes of the cosmopolitan cities, but, as we have seen, only the women adopt the linguistic habits symbolic of life in the modern city. In order to explain this gender-differentiated choice, we point to the fact that women's and men's positions in relation to their local society are very different. Women were (and are) in a much weaker position in terms of status and influence, and consequently in terms of the overall power they command. The weaker position of women can be explained with reference to participation in the local economy. In Jordan, women's participation in the labour force and involvement in political activity were almost non-existent during that period. They were thus altogether marginalised from the local economy and local politics. Commenting on such situations, Eckert (1989: 256) writes:

Since to have personal influence without power requires moral authority, women's influence depends primarily on the painstaking creation and elaboration of an image of the whole self as worthy of authority. Thus women are thrown into accumulation of symbolic capital...symbolic capital is the only kind that women can accumulate with impunity.

Following Eckert, we can say that deprived of power in public life women in Amman were forced to accumulate symbols of power and influence, such as speaking in a certain way, as the only way to assert status. Through its association with the dialects of the cosmopolitan cities, the glottal stop was seen as a symbol of belonging to influential social groups. As women increasingly adopted the glottal stop pronun- 
ciation of Qaf, this sound became associated with women's speech. It is not that the sound is intrinsically 'softer' or 'feminine', as one often reads in the literature regarding this variant of Qaf, but the fact that it is used more frequently by women is what gave rise to this association ${ }^{13}$.

The other side of the coin concerns the association of the use of $[\mathrm{g}]$ with male speech generally. Indeed, the data from Amman provide evidence that urban Palestinian men sometimes abandon the glottal stop in favour of $[\mathrm{g}]$. So, men's linguistic choices are also shaped by the social context, which requires explanation. Earlier in the article we alluded to the political turmoil that prevailed in Jordan as a direct result of the political situation in the region, especially in the aftermath of the occupation of the West Bank in 1967. In addition to the Palestinian refugees, Jordan hosted the Palestinian guerrilla movement (which later became the PLO). Tension in the country mounted as public services became overwhelmed by the number of refugees, which culminated in a bloody confrontation in 1970 and the expulsion of the Palestinian movement from the country. This event was a turning point in Jordan's internal politics, particularly insofar as the relations between the two sectors of the community (the Jordanians and the Palestinians) had to be redressed at the State level. In the decade that followed, the State appeared to follow a strategy whereby the Jordanians were increasingly granted a higher proportion of the appointments to high-ranking positions in the bureaucracy and civil service ${ }^{14}$. Consequently, this sector of the population assumed a firmer and more secure position, which resulted in general awareness of a distinctive Jordanian identity and adherence to local norms of social behaviour, including the local linguistic norms (also, see Al-Wer 2007: 61-62). There emerged therefore an association between the use of local linguistic features, local identity and political power. Women were totally excluded from the domains in which the use of the local linguistic features, such as $[\mathrm{g}]$, became a symbol of an individual's claim to power. As men increasingly used [g], this variant became associated with male speech, which explains the tendency seen by Palestinian men in the first and second generations to use this variant.

The 1980s and 1990's saw a period of relative political and social stability, in part a result of relative economic prosperity. The most

13. In this context, we may note that the glottal stop sound, which is used as a variant of the voiceless stops in many British dialects is generally perceived as 'coarse' as it is characteristic of inner city speech.

14. For a more detailed analysis of these events, see Al-Wer 1991 and Al-Wer 2007. 
crucial development for our current discussion is the creation of new job opportunities in the private sector, especially the financial sector and tourism, which created new types of employment for the younger generation in particular. Importantly, the new types of employment expanded the linguistic market of the glottal stop as a variant that symbolised supra-localism, transnational and cosmopolitan character. These attributes became important commodities for the mobile, outward and forward looking younger generations (of both sexes) in Amman. The glottal stop therefore acquired a new set of social meanings (in addition to the old meanings), which are relevant to the daily pursuits of the young man as well as the young woman in various arenas. This expansion in the value of the glottal stop was not achieved at the expense of the value of the local variant $[\mathrm{g}]$, but it proceeded alongside. As we have seen, the variant $[\mathrm{g}]$ continues to be a valuable commodity especially for the male speakers, and the old associations with male influence and machismo continue to exist and are functionalised when required by the context. For instance, it is normal for a young man in Amman to use $[\mathrm{g}]$ when interacting with male friends and to switch to [?] when addressing a young woman in the same group; or to use [g] when running an errand in a government office and to switch to [?] if he answers his phone in the same place. We can thus see that it is not an issue of one variant being prestigious while the other variant is stigmatised. In a sense neither is this or that. Rather, both variants are valuable commodities to have, and the sociolinguistically competent speakers know how to appropriate the variation to maximise benefit and minimise loss in social interaction.

The expansion in the use of the glottal stop can be taken to indicate a change in progress since all the young female speakers, regardless of their origins, use this variant consistently. Furthermore, regional koineisation clearly plays a role in advancing the glottal stop. This is however not to say that $[\mathrm{g}]$ will disappear from Amman in the foreseeable future, for although many of the developments in the Ammani dialect result in an overall convergence to a pan-Levantine norm at the phonological level, each dialect in the region has its peculiarities which serve to define the boundary of the speech community as a recognizable entity which is different from others. Amman is a Jordanian city and the variant $[\mathrm{g}]$ is recognised as a linguistic characteristic of the Jordanian variety of Levantine Arabic and, as we have seen, $[\mathrm{g}]$ is the majority variant outside the capital city. 


\section{Summary and conclusion: the lifecycle of Qaf}

Based on these data and analyses, it is possible to address some of the issues raised by Weinreich et al. (1968) with respect to four of the problems mentioned at the beginning of this article: constraints, transition, embedding and evaluation.

- The source of variation in Qaf in Jordan is a relatively recent innovation, which originated through contact with urban Levantine dialects, most importantly with urban Palestinian. The variation may have begun through borrowing of individual items containing the variant [?].

- The locus of the variation is definitely Amman. Although contact between the traditional Jordanian dialects and urban Levantine dialects has existed long before the Amman community grew, the data from the town of Sult in particular indicate that those members of the Sult community who were originally native speakers of urban Palestinian varieties converged to the Sult dialect and did not have an impact on variation in Qaf. It is also perfectly reasonable to suggest that there is a threshold below which innovations do not succeed. In other words, there had to exist enough speakers who used the glottal stop for the variation to become a community-wide norm. This was most certainly not the case in Sult, which became home to a handful of migrant families from various Levantine cities but not enough to influence its local dialect. The situation in Amman was completely different as neither sector of the population was native to the City, and the number of speakers of both types of dialects is probably roughly equal.

- Variation in Qaf first appeared in the speeches of Jordanian women and Palestinian men possibly during the late 1930s.

- The use of the glottal stop was relatively quickly diffused in the speech of women in Amman, especially during the period 1950-1970.

- As the occurrence of [?] increased steadily to replace [g] in the speech of women in Amman, it became associated with female speech, and it began to diffuse outside the city, affecting nearby areas such as the city of Sult before reaching farther away cities such as Ajloun. Amman has thus itself become the linguistic and cultural centre whose dialect is emulated elsewhere.

- During the 1970s men came under pressure, or were motivated, to use the local variant $[\mathrm{g}]$. Consequently, in addition to signifying a local Jordanian identity the variant $[\mathrm{g}]$ became associated with male speech.

- Social and political stability as well as economic growth during the 1980s and 1990s created a different environment. The community of Amman homogenised to some extent and acquired a native population 
(the third generation). In this environment, the association of the Qaf variants with ethnic origin became less significant, but new constraints on the use of the variants emerged. The new constraints included context and interlocutors.

- The change from [g] to [?] is at an advanced stage in the speech of women in the city (possibly completed). The shift from [g] to [?] may be accelerated by regional koineisation.

- The change has not yet been totally embedded in the community and the dialect. The variant $[\mathrm{g}]$ continues to be functional, especially for male speakers. This group of speakers use both variants in various contexts.

- The old social constraints on the variation have not disappeared, but have been complicated by the addition of new constraints. The Jordanian speakers in Amman continue to use [g], often as a marker of Jordanian identity. In Amman, where the use of the glottal stop is most advanced, the variant $[\mathrm{g}]$ continues to be functional especially for the male speakers from both dialectal backgrounds. Outside the capital city, [g] continues to be the norm.

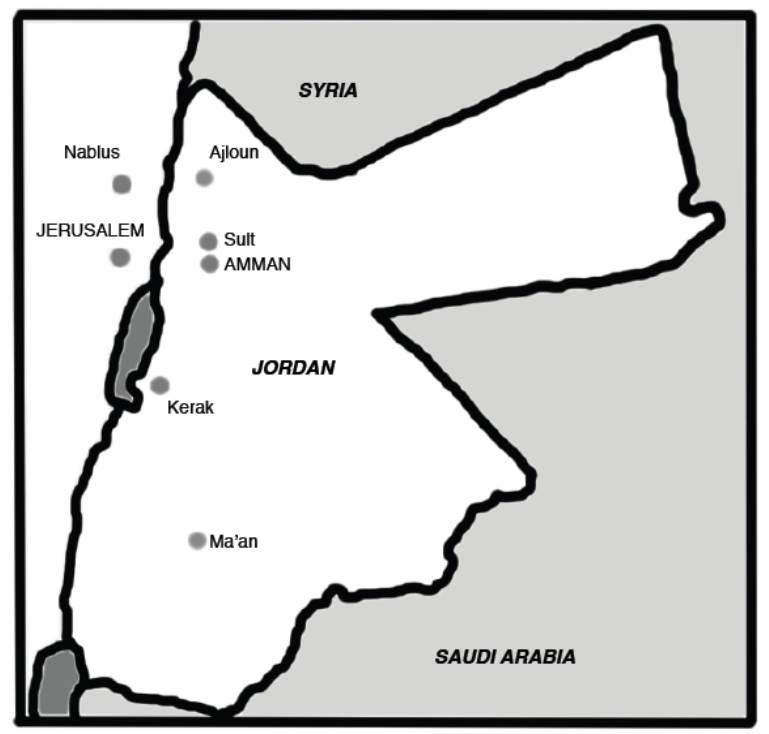

Map of Jordan showing the locations of the cities referred to in the article 


\section{References}

Abdel-Jawad H. (1981), Lexical and Phonological Variation in Spoken Arabic of Amman, Ph.D. thesis, University of Pennsylvania.

Al-Khatib M. (1988), Sociolinguistic Change in an Expanding Urban Context, Ph.D. thesis, University of Durham.

Al-Wer E. (1991), Phonological variation in the speech of women from three urban areas in Jordan, Ph.D. thesis, University of Essex.

- (2002), Jordanian and Palestinian dialects in contact: vowel raising in Amman, in M. Jones \& E. Esch (eds), Language Change. The interplay of internal, external and Extra-linguistic factors, Berlin, Mouton de Gruyter (p. 63-79).

- (2003), New dialect formation: the focusing of -kum in Amman, in D. Britain \& J. Cheshire (eds), Social Dialectology: In Honour of Peter Trudgill, Amsterdam, Benjamins (p. 59-67).

- (2007), The Formation of the Dialect of Amman, in C. Miller, E. AlWer, D. Caubet \& J.C.E. Watson (eds), Arabic in the City. Issues in dialect contact and language variation, New York/London, Routledge (p. 55-76).

Bergsträsser G. (1915), Sprachatlas von Syrien und Palästina, Zeitschrift des DeutschenPalästina-Vereins, 38, p. 169-222.

Cleveland R. (1963), A Classification for the Arabic Dialects of Jordan, Bulletin of the American Schools of Oriental Research, 171, p. 56-63.

Eckert P. (1989), The whole woman: Sex and gender differences in variation, Language Variation and Change, 1, p. 245-267.

Haeri N. (1997), The Sociolinguistic Market in Cairo: Gender, Class, and Education, London, Kegan Paul International.

Herin B. (2010), Le parler arabe de Salt. Phonologie, morphologie et éléments de syntaxe, Ph.D. thesis, Université Libre de Bruxelles.

Labov W. (1994), Principles of Linguistic Change: Internal Factors, Oxford, Blackwell.

Milroy J., Milroy L., Hartley S. \& Walshaw D. (1994), Glottal stops and Tyneside glottalisation: competing patterns of variation and change in British English, Language Variation and Change, 6, p. 327-357. 
Trudgill P. (2004), New-dialect Formation: The Inevitability of Colonial Englishes, Edinburgh, Edinburgh University Press.

Weinreich U., Labov W. \& Herzog, M.I. (1968), Empirical Foundations for a Theory of Language Change, Austin, University of Texas Press. 